\title{
Tissue distribution of striped jack nervous necrosis virus (SJNNV) in adult striped jack
}

\author{
H. D. Nguyen ${ }^{1}$, K. Mushiake ${ }^{2}$, T. Nakai ${ }^{1, *}$, K. Muroga ${ }^{1}$ \\ ${ }^{1}$ Fish Pathology Laboratory, Faculty of Applied Biological Science, Hiroshima University, Higashihiroshima 739, Japan \\ ${ }^{2}$ Komame Station, Japan Sea-Farming Association, Otsuki-cho, Kochi 788-03, Japan
}

\begin{abstract}
Fluorescent antibody technique (FAT) and polymerase chain reaction (PCR) method were used to localize striped jack nervous necrosis virus (SJNNV, a nodavirus) in adult striped jack Pseudocaranx dentex. One group of brood stocks $(N=4)$ consisted of 13 -yr-old spawners whose reproductive fluids were SJNNV-positive by the PCR test. The other group $(N=4)$ consisted of 4 -yr-old fish which had not previously spawned whose reproductive fluids were negative by the PCR test. Positive FAT reactions using an anti-SJNNV rabbit serum were observed in the gonad, intestine, stomach, kidney, and liver of the 13-yr-old fish but not in the corresponding organs of the 4-yr-old fish. In neither group were the viral antigens detected in the spinal cord, brain, or retina tissues, the target organs of the virus in striped jack larvae. The FAT results were consistent with PCR results for the detection of the SJNNV coat protein gene. The present results suggest that SJNNV originates in various organs of striped jack spawners and is shed from the intestine and gonad, which results in contamination of eggs.
\end{abstract}

KEY WORDS: Viral nervous necrosis (VNN) - Nodavirus - Striped jack · FAT PCR Pseudocaranx dentex Brood stock

\section{INTRODUCTION}

Viral nervous necrosis (VNN) is a threat to hatchery production of larvae and juveniles of marine fish worldwide, and the number of fish species affected by the disease has been rapidly increasing (Muroga 1995, Nakai et al. 1995). Affected fish are characterized by a corkscrew or whirling swimming behavior; the affected central nervous tissues and retina contain areas of necrosis with conspicuous vacuolation and there are small spherical virus particles $(25$ to $30 \mathrm{~nm}$ in diameter) in the cytoplasm of the nerve cells. Three viruses have been purified from affected fish and classified as new members of the family Nodaviridae. These are striped jack nervous necrosis virus (SJNNV) from striped jack Pseudocaranx dentex (Mori et al. 1992) and fish encephalitis viruses (FEVs) from barramundi Lates calcarifer and from sea bass Dicentrarchus labrax (Comps et al. 1994).

- Addressee for correspondence.

E-mail: nakaitt@ipc.hiroshima-u.ac.jp
Various specific diagnostic methods for VNN have been developed. These include enzyme-linked immunosorbent assay (ELISA) (Arimoto et al. 1992) and the fluorescent antibody technique (FAT) (Nguyen et al. 1996) for virus antigen detection and reverse transcription polymerase chain reaction (RT-PCR) amplification for detection of the coat protein gene (RNA2) of SJNNV (Nishizawa et al. 1994). Using these methods, SJNNV was detected from the gonad of adult striped jack during spawning seasons, and thus the brood stocks were found to be an important virus reservoir (Arimoto et al. 1992, Mushiake et al. 1992). Subsequently, segregation of virus-carrying fish (based on PCR tests) from brood stocks prior to spawning has proved to be efficient in controlling VNN in striped jack larvae (Mushiake et al. 1994). The results of Mushiake et al. (1994) also indicated that SJNNV multiplied in organs other than the gonads, because some spawners (male and female) that tested SJNNVnegative when the PCR test was applied to gonad materials tested positive when plasma antibodies were examined. An interesting problem remains, namely, 
which organs are most responsible for virus multiplication or chronic virus infection in adult striped jack. The present study was conducted to investigate the distribution of SJNNV in tissues of striped jack brood stocks by means of the FAT and PCR methods.

\section{MATERIALS AND METHODS}

Striped jack brood stocks examined. Larval production of striped jack was conducted using 12 spawners ( 5 males and 7 females, 13 yr of age) at the Komame Station of the Japan Sea-Farming Association (JASFA) from February to March 1994. VNN occurred within 2 d after hatching among larvae produced from the spawners at the 22nd spawning. Four spawners (2 males and 2 females; 4.9 to $6.0 \mathrm{~kg}$ in body weight) from this group, in whose reproductive fluids SJNNV had been detected by a PCR test made prior to the $22 \mathrm{nd}$ spawning, were sacrificed just after the 22nd spawning. The eyes, brain, spinal cord, gills, skeletal muscle and other internal organs (gonad, heart, spleen, liver, kidney, stomach, and intestine) of these fish were collected and fixed in 10\% phosphate buffered formalin ( $\mathrm{pH} 7.4$ ). For comparison, 4 fish (1 male and 3 females; 2.0 to $2.5 \mathrm{~kg}$ in body weight) from 4 -yr-old striped jack brood stocks reared at the same JASFA station were àlso sacrificed in June 1995. These fish had not spawned up to that time and SJNNV had not been detected by the PCR test in their reproductive fluids. The tissue samples were collected and fixed in the samc way as described above.

Fluorescent antibody technique. Formalin-fixed samples were dehydrated and embedded in paraffin wax (solidification point: 56 to $58^{\circ} \mathrm{C}$ ). Paraffin sections of 3 to $5 \mu \mathrm{m}$ thickness prepared on glass slides were deparaffinized with warm xylene and re-hydrated through a graded series of alcohol. The sections were then treated with $0.1 \%$ trypsin in $0.01 \mathrm{M}$ phosphate buffered saline (PBS, pH 7.4) for 30 min at $37^{\circ} \mathrm{C}$. An anti-SJNNV rabbit serum employed in a previous study (Nguyen et al. 1996), which was raised against purified virions of SJNNV according to the procedures described previously (Arimoto et al. 1992, Mori et al 1992), was used for the detection of SJNNV antigens. After rinsing with PBS, the sections were incubated with the anti-SJNNV rabbit serum, which had been diluted $1: 100$ in PBS containing $2 \%$ bovine serum albumin, at $37^{\circ} \mathrm{C}$ for $30 \mathrm{~min}$. After rinsing with PBS, slides were incubated with FITC(fluorescein isothiocyanate)-conjugated swine Ig to rabbit Ig (Dako) at $37^{\circ} \mathrm{C}$ for $30 \mathrm{~min}$. The slides were washed, mounted with buffered glycerin $\mathrm{pH}$ 9.2), and examined with a fluorescence microscope (Nikon EDF). As a negative control, the anti-SJNNV serum was replaced with normal rabbit serum diluted 1:100.

Histological examination and electron microscopy. For histological observation, the same sections as used in the FAT test were washed thoroughly with PBS and re-stained with haematoxylin-eosin ( $\mathrm{H} \& \mathrm{E})$, Berlin blue or Fontana-Masson staining. Formalin-fixed samples were re-fixed in a $2.5 \%$ glutaraldehyde $/ 2 \%$ paraformaldehyde mixture ( $\mathrm{pH} 7.4$ ), post-fixed with $1 \%$ osmium tetroxide, and embedded in Quetol-812 (Oken). Thin sections were stained with $1 \%$ uranyl acetate and $1 \%$ lead citrate, and then examined with Hitachi $\mathrm{H}-600 \mathrm{~A}$ electron microscope at $80 \mathrm{kV}$ accelerating voltage.

Detection of the virus by PCR. Aliquots of the samples used for the FAT test were homogenized with DEPC (diethyl pyrocarbonate)-treated water $10.5 \%$ Tween $20,0.5 \mathrm{mg} \mathrm{ml}^{-1}$ proteinase $\mathrm{K}$ ). After incubation at $37^{\circ} \mathrm{C}$ for $30 \mathrm{~min}$, the total nucleic acids were extracted with phenol and chloroform-isoamyl alcohol. PCR amplification was carried out using a primer set designed for the $\mathrm{T} 4$ region ( $430 \mathrm{bp}$ ) in the open reading frame of the SJNNV coat protein gene, according to the method described previously (Nishizawa et al. 1994).

Table 1. Detection of SJNNV antigens from striped jack brood stocks using the fluorescent ant body technique (FAT). The results were completely consistent with those of the PCR test except for the eye, for which only fish No. 3 was positive. Other: brain, spinal cord, gills, spleen, heart, muscles

\begin{tabular}{|c|c|c|c|c|c|c|c|c|c|c|}
\hline \multicolumn{4}{|c|}{ Fish examined } & \multicolumn{7}{|c|}{ Results of SJNNV detection by FAT } \\
\hline No. & Age (yr) & Sex & Body wt $(\mathrm{kg})$ & Eye & Gonad & Liver & Kidney & Intestine & Stomach & Other \\
\hline 1 & 13 & Male & 4.9 & + & + & + & + & + & - & -. \\
\hline 2 & 13 & Male & 4.9 & + & + & + & + & + & + & - \\
\hline 3 & 13 & Female & 5.9 & + & + & - & + & + & + & - \\
\hline 4 & 13 & Female & 6.0 & + & + & + & - & + & + & - \\
\hline 5 & 4 & Male & 2.3 & + & - & - & - & - & - & - \\
\hline 6 & 4 & Female & 2.0 & + & - & - & - & - & - & - \\
\hline 7 & 4 & Female & 2.5 & + & - & - & - & - & - & - \\
\hline 8 & 4. & Female & 2.4 & + & - & - & - & - & - & - \\
\hline
\end{tabular}




\section{RESULTS}

In 13-yr-old fish whose reproductive fluids were SJNNV-positive in the PCR test, specific fluorescence indicating the presence of SJNNV antigens was observed in low amounts in the epithelial cells of bile ducts in the liver, the mucosal epithelium of the posterior intestine and stomach, the tubular epithelial cells of the kidney, and the atretic oocytes of the ovary, but not in the gills, brain, spinal cord, heart, spleen, or skeletal muscle (Table 1). PCR-based detection of the virus yielded positive results only for those organs which were positive based on FAT Histopathological changes were not found either in the FAT-positive or FAT-negative tissues examined. Using FAT, a clear fluorescence was also detected in the choroidal layer of the eyes of all the fish examined, but this result was not consistent with that of the PCR test in which only 1 of 4 fish examined was positive. Light microscopy revealed that the areas in the choroidal layer showing a positive FAT reaction were composed of clumps of pigmented cells which appeared brown with H\&E staining (Figs. 1 \& 2). The pigments were confirmed to be melanins as they were stained dark brown in Fontana
Fig. 1. Pseudocaranx dentex. Specific fluorescence larrowheads) in the eye choroid of a 13-yr-old striped jack revealed by the fluorescent antibody technique (FAT). Scale bar = $50 \mu \mathrm{m}$

Fig. 2. Pseudocaranx dentex. Melano-macrophage aggregates (arrowheads) in the eye choroid of a 13-yr-old striped jack revealed by H\&E staining. Note that these melanomacrophage aggregates are positive in FAT (Fig. 1). Scale bar $=50 \mu \mathrm{m}$
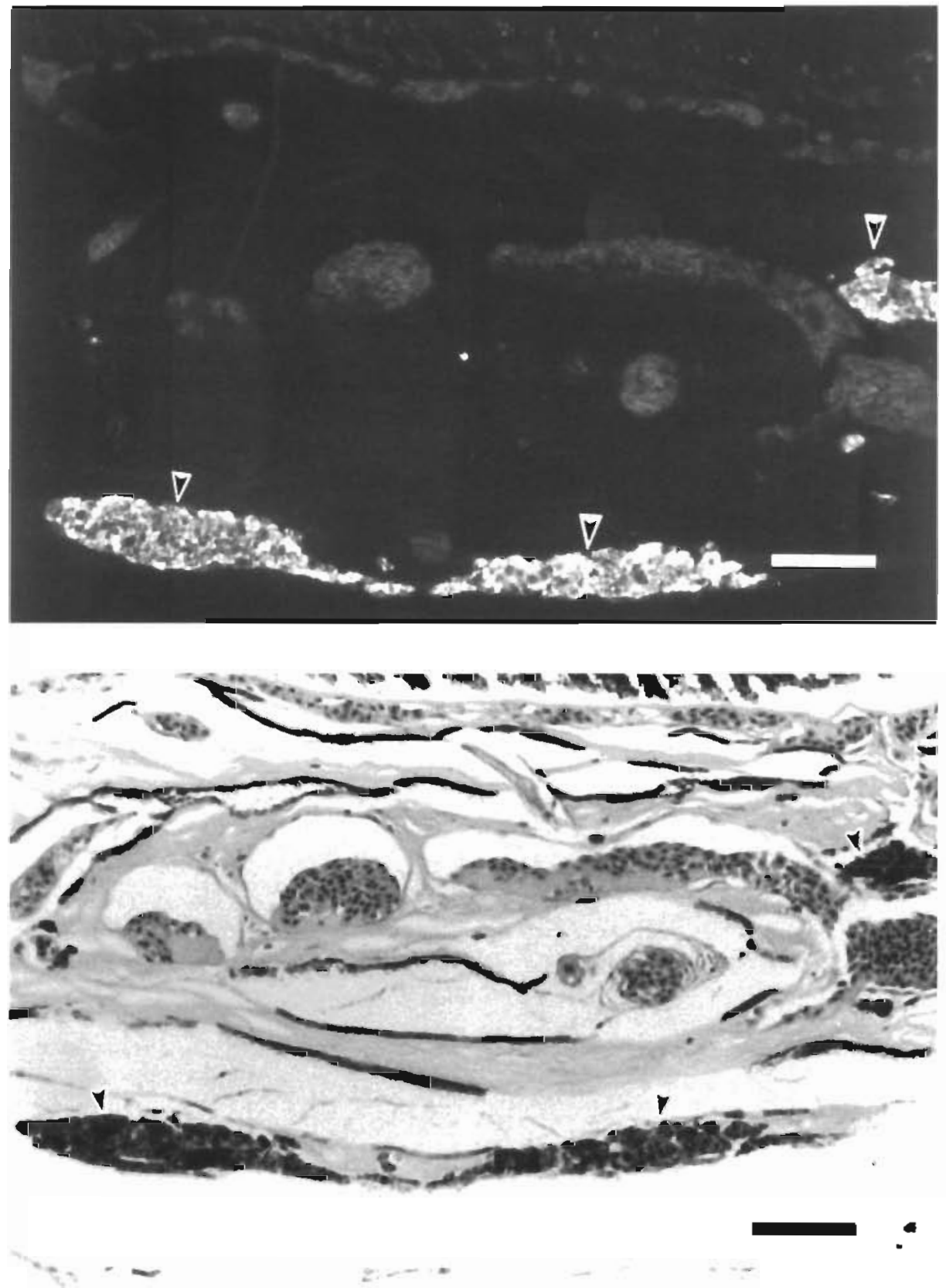
Masson staining and discolored by a bleaching method for melanins using potassium permanganate/oxalic acid, but did not stain blue with Berlin blue for hemosiderin. Electron microscopy was carried out on the FAT-positive organs (gonads, liver, kidney, stomach, intestine, and eye), but already defined virus particles were not found in any samples examined.

A specific FAT reaction was observed only in melanin-containing cells located in the choroidal layer of the eyes of all four 4 -yr-old fish, which were SJNNVnegative based on a PCR test of their reproductive fluids (Table 1). However, all of the samples, including the eye tissues, were negative in the PCR test. Light microscopy did not reveal any histopathological changes in these tissues. SJNNV particles were not detected by electron microscopy in the choroidal layer of the eye.

\section{DISCUSSION}

The distribution of SJNNV in the tissues of adult fish was studied in 2 groups of striped jack brood stocks. According to a RT-PCR test of gonadal fluid, one group was composed of SJNNV-positive fish (13-yr-olds) and the other was composed of SJNNV-negative fish (4-yrolds). FAT and PCR tests revealed that SJNNV was present not only in the gonad but also in other organs (liver, kidney, stomach, and intestine) of the 13-yr-old brood stocks. However, viral antigens were not detected in these organs in the 4 -yr-old fish. These observations indicate that striped jack brood stocks which have already spawned several times (13-yr-old fish) carry SJNNV in various organs including the gonad. During the stress of spawning it is thought that the virus replicates and is distributed to these organs. The replicated virus can then be shed from the gonads and digestive tracts, resulting in contamination of eggs and hatched larvae (Arimoto et al. 1992, Mushiake et al. 1993). Thus, as we mentioned in a previous study (Mushiake et al. 1994), reducing stress to the brood stocks prior to and during spawning is important in order to reduce the frequency of outbreaks of VNN in their larvae.

Positive fluorescence found in the FAT test was also observed in melano-macrophages of the eye choroid of all the fish examined, in both the 13-yr-old and 4-yrold groups. The specificity of the antiserum against viral antigen(s) was indicated in a supplementary experiment which showed that the eye choroid in two of ten 4-yr-old fish collected at the Komame Station in February 1996 were negative for the FAT reaction. The positive reaction was not directed against a common host retinal antigen. However, the PCR test and electron microscopy were negative and failed to confirm the presence of the virus in the eye choroid. In the present study, electron microscopy could not clearly demonstrate the presence of the virus in the eye choroid or in other tissues which were positive using the FAT test. It may be difficult to find extremely small spherical virions (25 nm) when they are present in low numbers and do not form crystalline array arrangements, which are usually observed in the nerve cells of infected striped jack larvae (Nguyen et al. 1996). Another method similar to immuno-electron microscopy will be needed to detect the virus when it occurs in low concentrations in carrier fish.

It is noteworthy that SJNNV antigens were not detected in the brain, spinal cord or retina of any of the fish examined; this indicates that the major difference between carrier fish and affected fish is the spread of the virus to these nerve tissues in affected fish. VNN usually occurs only in larval or juvenile fish (Nakai et al. 1995); however, mass mortalities due to VNN have recently been observed in adult sevenband grouper Epinephelus septemfasciatus (Fukuda et al. 1996). High levels of virus multiplication were confirmed in the central nervous tissues and retina of these affected adult fish. Therefore, if the defence system of host fish is highly disturbed under stress conditions, VNN disease will occur even in adult fish that carry the virus.

\section{LITERATURE CITED}

Arimoto M, Mushiake K, Mizuta Y, Nakai T, Muroga K, Furusawa I (1992) Detection of striped jack nervous necrosis virus (SJNNV) by enzyme-linked immunosorbent assay (ELISA). Fish Pathol 27:191-195

Comps M, Pepin JF, Bonami JR (1994) Purification and characterization of two fish encephalitis viruses (FEV) infecting Lates calcanfer and Dicentrarchus labrax. Aquaculture 123:1-10

Fukuda Y, Nguyen HD, Furuhashi M, Nakai T (1996) Mass mortality of cultured sevenband grouper, Epinephelus septemfasciatus, associated with viral nervous necrosis. Fish Pathol 31:165-170

Mori K, Nakai T, Muroga K, Arimoto M, Mushiake K, Furusawa I (1992) Properties of a new virus belonging to Nodaviridae found in larval striped jack (Pseudocaranx dentex) with nervous necrosis. Virology 187:368-371

Muroga K (1995) Viral and bacterial diseases in larval and juvenile marine fish and shellfish: a review. Fish Pathol 30:71-85 (in Japanese)

Mushiake K, Arimoto M. Furusawa T, Furusawa I, Nakai T, Muroga K (1992) Detection of antibodies against struped jack nervous necrosis virus (SJNNV) from brood stocks of striped jack. Nippon Suisan Gakkaishi 58:2351-2356

Mushiake K, Nakai T, Muroga K, Sekiya S, Furusawa I (1993) Viral nervous necrosis (VNN) of striped jack: effects of plasma antibody level of spawners and spawning condltions on the occurrence of the disease in their offsprings Suisanzoshoku 41:327-332 (in Japanese)

Mushiake K, Nishizawa T, Nakai T, Furusawa I, Muroga K (1994) Control of VNN in striped jack: selection of spawners based on the detection of SJNNV gene by polymerase chain reaction (PCR). Fish Pathol 29:177-182 
Nakai T, Mori K, Nishizawa T, Muroga K (1995) Viral nervous necrosis of larval and juvenile marine fish. Proceedings of the International Symposium on Biotechnology Applications in Aquaculture, Asian Fisheries Society Special Publication No. 10, National Taiwan University, Taipei, p $147-152$

Nguyen HD, Nakai T, Muroga K (1996) Progression of striped

Responsible Subject Editor: J.-A. Leong, Corvallis, Oregon, USA jack nervous necrosis virus (SJNNV) infection in naturally and experimentally infected striped jack Pseudocaranx dentex larvae. Dis Aquat Org 24:99-105

Nishizawa T, Mori K, Nakai T, Furusawa I, Muroga K (1994) Polymerase chain reaction (PCR) amplification of RNA of striped jack nervous necrosis virus (SJNNV). Dis Aquat Org 18:103-107

Manuscript first received: September 20, 1996 Revised version accepted: October 14, 1996 